\title{
SOLAR ENERGY PHOTOCONVERSION:
}

The solar energy photoconversion symposium highlighted research and development and production activity in both photovoltaic and photoelectrochemical solar conversion technologies. The symposium assembled eight invited and nineteen contributed papers representing major advances, reviews and projections for these photoconversion methods dealing with the production of electricty and chemicals (fuels). The two-day session was keynoted by Adam Heller of Bell Laboratories, with a review of the chemistry of the radiationless recombination processes of the photogenerated carriers that control the performance and efficiencies of these photovoltaic and photoelectrochemical devices. Heller stressed the importance of surfaces, grain boundaries and lattice defects in photoconversion mechanisms, and reviewed processes for minimizing or passivating their deleterious effects upon cell performance and operating lifetime. Contributed papers by Kazmerski of the Solar Energy Research Institute on interface formation and stability in $\mathrm{CuInSe}_{2}$ heterojunction solar cells, and by Allen of SES Inc., on electromigration of copper ions in $\mathrm{Cu}_{2} \mathrm{~S}$-based solar cells, complemented Heller's opening remarks on polycrystalline devices. The latter presentation emphasized the controlling influence of the various cell interfaces on the temperature stability of thin-film, 10\%-efficient, $\mathrm{Cd}(\mathrm{Zn}) \mathrm{S} / \mathrm{CuInSe}_{2}$ solar cells. The former provided information on the origin and control of the major degradation mechanism $(\mathrm{Cu}$ migration) in the $\mathrm{Cu}_{2} / \mathrm{CdS}$ cell.

A highlight of the first day--and, indeed, the entire symposium--was the presentation by Stanford $R$. Ovshinsky, president and founder of Energy Conversion Devices of Troy, Mich. Ovshinsky, a pioneer in

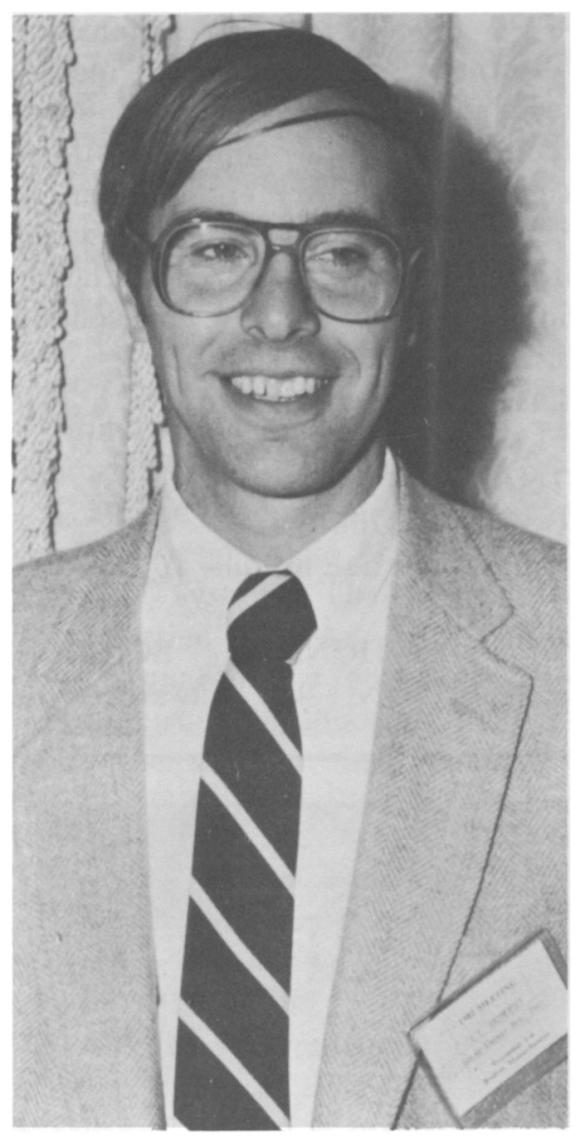

multichamber cell production systems that continuously coat one foot wide flexible stainless steel ribbon with amorphous cells, with a $3 \mathrm{MW} / \mathrm{yr}$ production capability. Ovshinsky expects cells in the $11 \%-12 \%$ range maximum for single junction devices, but over $30 \%$ for tandem cells which he says will represent no added cost over single cells. Ovshinsky demonstrated the large-scale production capabilities of his system with a slide of a 1,000 foot long, 1 foot wide tandem amorphous solar cell.

Two contributed papers dealing with the thermal annealing of amorphous $\mathrm{Si}: \mathrm{H}$ cells (M.K. Han, SUNY) and the characterization of a-Si:Sn:H alloys (D.L.Williamson, Colorado School of Mines and SERI) were also presented.

The stability of electrodes in photoelectrochemical cells was discussed in an invited presentation by A. J. Bard of the University of Texas. Incorporation of silicides (Pt, Ir, Ru) and utilization of catalysts provide stable $\mathrm{Si}$ photoelectrodes. The status of amorphous hydrogenated $\mathrm{Si}$ electrodes was presented by G. S. Calabrese of M.I.T. Although cost considerations favor this material, photovoltages have been limited. Large area thinfilm CdSe electrochemical cells with efficiencies in excess of $6 \%$ were reported by R. D. Rauh of EIC Laboratories. Areas up to $400 \mathrm{~cm}^{2}$ for these cells have been tested.

Grain boundary limitations in polycrystalline $\mathrm{Si}$ cells formed the subject of a group of papers by P. E. Russell, S.E.R.I, E. S. Yang, Columbia University, J. I. Hanoka, Mobil Tyco, S. J. Fonash, Pennsylvania State University, W. F. Regnault, Semix Inc., and J. S. Song, Columbia University. The invited paper by Russell and Yang focused on the role of impurities - specifically 
oxygen - on the electrical activity of the intergrain regions. Fonash reported that the degree of activation depends significantly upon the thermal and process history of the polysilicon. Hanoka reported an improvement in efficiency (from $8.4 \%$ to $9.5 \%$ ) of hydrogen passivated EFG silicon. Antireflection coated ribbons exhibited efficiencies of up to $14 \%$ following hydrogen treatment. Semix reported on the differences in grain boundary behavior with structural and orientational properties. A model for polycrystalline $\mathrm{Si}$ photoconductivity was covered by J. S. Song.

A near-commercialization photoelectrochemical system was reviewed by E. L. Johnson of Texas Instruments. This system uses small, $(0.02 \mathrm{~cm})$ single crystal $\mathrm{Si}$ cells embedded in glass ribbon to produce both electricity and fuel from a $\mathrm{HBr}$ electrolyte. Modules are $4^{\prime} \times 8^{\prime \prime}$ in size, with 700 watt-hour storage. Systems have 11-12\% solar-electricity efficiency, and $\sim 8$ solar-chemical efficiency. Accelerated life tests indicated better than 20 year lifetime.

Ted Ciszek of S.E.R.I. reviewed the status of silicon sheet technologies for photovoltaics. He catagorized the sheet technologies into: (1) those with small meniscus height, (2) those with large meniscus height, and (3) those that achieve high growth rates through use of an extended meniscus. Features and difficulties associated with the various technologies, EFG, ESP, RAD, web, etc., were discussed. None of the processes presently delivers $\mathrm{Si}$ sheet with: (1) good crystal quality, (2) smooth surfaces, (3) high purity, (4) easy process control, and (5) high throughput and production rate. Stable metal-insulator-semiconductor solar cells of $\mathrm{Yb}$ on polycrystalline $\mathrm{Si}$ were reported by G. Rajeswaran of SUNY - Buffalo. F. W. Saris of FOM
- Institute for Atomic and Molecular Physics, The Netherlands, discussed the beneficial effects of thermal and laser annealing on $\mathrm{Si}$ solar cell performance.

An invited review by J. C. C. an of M.I.T. Lincoln Lab provided insights into the use of II-VI and III-V materials for photovoltaic applications. Fan concluded that III$V$ materials such as GaAs are best utilized in high efficiency solar cells. In fact, past attempts at the use of poly-GaAs and InP have suffered due to severe grain boundary pinning problems. For example, grain boundaries in InP are most probably pinned to make them n-type, and use of ITO as a hetrojunction partner leads to formation of $n-n$ junctions at

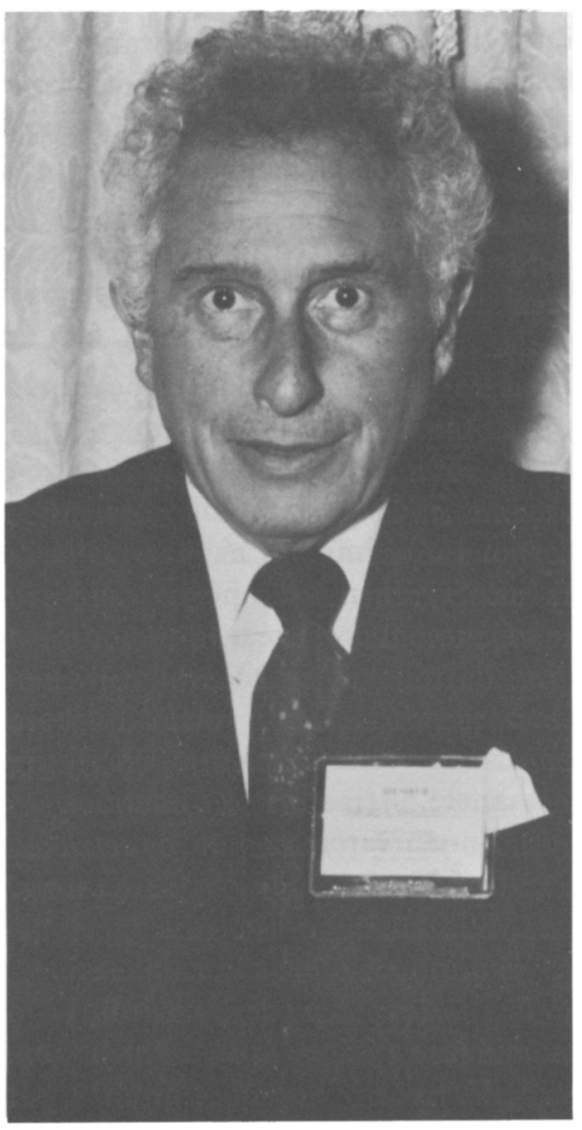

S.R. Ovshinsky the grain boundaries. In the II-VI area, R. L. Turcotte of Radiation Monitoring Devices, reported on sprayed CdTe thin film cells. Problems in phase identification of $\mathrm{Cu}_{x} \mathrm{~S}$ were discussed by $\mathrm{L}$. $\mathrm{F}$. Donaghey of Chevron Research. Significantly, he reported that $x$-ray diffraction peaks had been frequently misinterpreted in prior work.

In the final session of the symposium, M. Ludowise of Varian Associates reviewed advanced, multijunction concentrator cell research. Current $R$ \& $D$ is directed towards production of a $30 \%$ efficient, two-junction device for 400 suns in a terrestrial environment, and a threejunction device for use in space under $100 \mathrm{x}$ concentration. Prototype GaAlAs/GaAs cells have demonstrated $22 \%$ efficiency at 130 AM3 suns, the highest for any multijunction cell reported to date. Several approaches to monolithic device structures were presented, including two, three, and four terminal devices. Spectral splitting concepts were also reviewed. Major problems for the multijunction approach involve efficiency improvement, AR coating, current matching, stability, cell interconnect methodology, and layer thickness and property control. Solid solutions of photovoltaic materials were discussed by J. V. Masi, Western New England College. Transparent electrodes were reported by $H$. E. Hager of the University of Washington $\left(\mathrm{SnO}_{2}\right)$ and S. C. Miller of ARCO Solar $\left(\mathrm{SnO}_{2}\right.$ doped with F). The importance of these transparent contacts was demonstrated in each case.

\section{M.S. WRIGHTON}

Massachusetts Institute of Technology

L.L. KAZMERSKI

Solar Energy Research Institute 